\title{
Papain-Like Protease 2 (PLP2) from Severe Acute Respiratory Syndrome Coronavirus (SARS-CoV): Expression, Purification, Characterization, and Inhibition ${ }^{\dagger}$
}

\author{
Yu-San Han, ${ }^{\ddagger}$ Gu-Gang Chang, ${ }^{\S}$ Chiun-Gung Juo, ${ }^{\|}$Hong-Jen Lee,,${ }^{\ddagger}$ Shiou-Hwei Yeh,${ }^{\perp}$ John Tsu-An Hsu, ${ }^{\ddagger}$ and \\ Xin Chen*," \\ Division of Biotechnology and Pharmaceutical Research, National Health Research Institutes, Miaoli County, Taiwan 350, \\ Republic of China, Faculty of Life Science, National Yang-Ming University, Taipei, Taiwan 112, Republic of China, Institute of \\ Biomedical Sciences, Academia Sinica, Taipei, Taiwan 115, Republic of China, Division of Molecular and Genomic Medicine, \\ National Health Research Institutes, Miaoli County, Taiwan 350, Republic of China
}

Received March 14, 2005; Revised Manuscript Received May 24, 2005

\begin{abstract}
Viral proteases are essential for pathogenesis and virulence of severe acute respiratory syndrome coronavirus (SARS-CoV). Little information is available on SARS-CoV papain-like protease 2 (PLP2), and development of inhibitors against PLP2 is attractive for antiviral therapy. Here, we report the characterization of SARS-CoV PLP2 (from residues 1414 to 1858) purified from baculovirus-infected insect cells. We demonstrate that SARS-CoV PLP2 by itself differentially cleaves between the amino acids Gly180 and Ala181, Gly818 and Ala819, and Gly2740 and Lys2741 of the viral polypeptide pp1a, as determined by reversed-phase high-performance liquid chromatography analysis coupled with mass spectrometry. This protease is especially selective for the P1, P4, and P6 sites of the substrate. The study demonstrates, for the first time among coronaviral PLPs, that the reaction mechanism of SARS-CoV PLP2 is characteristic of papain and compatible with the involvement of the catalytic dyad (Cys)-S ${ }^{-} /$ (His)- $\mathrm{Im}^{+} \mathrm{H}$ ion pair. With a fluorogenic inhibitor-screening platform, we show that zinc ion and its conjugates potently inhibit the enzymatic activity of SARS-CoV PLP2. In addition, we provided evidence for evolutionary reclassification of SARS-CoV. The results provide important insights into the biochemical properties of the coronaviral PLP family and a promising therapeutic way to fight SARS-CoV.
\end{abstract}

Severe acute respiratory syndrome (SARS) ${ }^{1}$ is a lifethreatening atypical pneumonia caused by SARS coronavirus (SARS-CoV) (1, 2). SARS-CoV belongs to the coronaviruses (order Nidovirales, family Coronaviridae, genus Coronavirus), which are enveloped positive-stranded RNA viruses (35). Its RNA is $29.7 \mathrm{~kb}$ in length and encodes structural proteins and two large nonstructural polypeptides, ppla (486

This study was supported by Grants 92-2751-B-400-006-Y and 932751-B-400-002-Y from National Science Council, Taiwan, and by National Health Research Institutes, Miaoli, Taiwan, Republic of China, to X.C.

* To whom correspondence should be addressed: Division of Biotechnology and Pharmaceutical Research, National Health Research Institutes, Miaoli County, Taiwan 350, Republic of China. Telephone: 88637246166ext.35718.Fax: 88637586456.E-mail: xchen@nhri.org.tw.

$¥$ Division of Biotechnology and Pharmaceutical Research, National Health Research Institutes.

$\S$ National Yang-Ming University.

"Academia Sinica.

${ }^{\perp}$ Division of Molecular and Genomic Medicine, National Health Research Institutes.

${ }^{1}$ Abbreviations: SARS, severe acute respiratory syndrome; PLP2, papain-like proteinase 2; 3CL, 3C-like protease; SARS-CoV, severe acute respiratory syndrome coronavirus; IBV, infectious bronchitis virus; $\mathrm{MHV}$, murine hepatitis virus; $\mathrm{HCoV}-229 \mathrm{E}$, human coronavirus 229E; FMDV, foot-mouth disease virus; $\mathrm{BCoV}$, bovine coronavirus; nsp, nonstructural protein; RP-HPLC, reverse-phase high-performance liquid chromatography; MALDI-TOF MS, matrix-assisted laser desorption/ionization time-of-flight mass spectroscopy; Abz, o-aminobenzoyl; EDDNP, $N$-ethylenediamine-2,4-dinitrophenylamide; FRET, fluorescence resonance energy transfer.
$\mathrm{kDa})$ and pplab (790 kDa) $(3,4)$. These two nonstructural polypeptides undergo co-translational processing that results in various nonstructural proteins (nsp's) (Figure 1). It is generally believed that the processing of ppla and pplab is performed by two viral-encoded proteases, 3C-like protease (3CL) and papain-like protease 2 (PLP2), encoded on pp1a (Figure 1) $(6-8)$. SARS-CoV and infectious bronchitis virus (IBV) contain only one PLP domain, whereas both murine hepatitis virus (MHV) and human coronavirus 229E (HCoV229E) have two paralogous PLP domains, PLP1 and PLP2 $(9-18)$. The classification of the PLP1 or PLP2 domain is based on its location in the nsp. The following domains are usually organized in the sequential order: acidic (Ac), PLP1, $\mathrm{X}, \mathrm{PLP} 2$, and Y domains $(6,14)$. Because the PLP domains of both SARS-CoV and IBV are located between the $\mathrm{X}$ and Y domains, they are considered orthologues of PLP2 (Figure 1) $(6,14)$. These viral proteases are essential for viral pathogenesis and virulence. Therefore, one possible approach to containing and resolving the global threat of a SARS epidemic is the development of efficacious anti-SARS drugs targeting these proteases. However, little information is available on the enzymatic properties and the substrate specificity of SARS-CoV PLP2. Nor do we have information on the differences between coronaviral PLP1 and PLP2 for achieving inhibition specificity. 


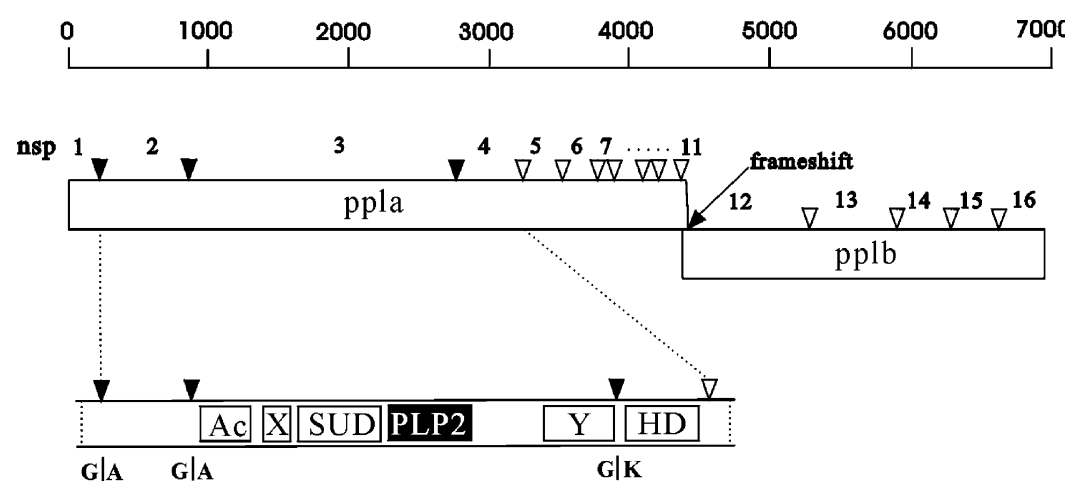

FIGURE 1: Predicted cleavage sites of SARS-CoV PLP2. The amino acid numbering corresponding to the SARS-CoV nonstructural polypeptide (nsp) is marked in the top panel. ppla and pplb are the two nonstructural polypeptides before they are cleaved and processed by viral proteases. In the middle panel, the filled triangles mark the sites predicted to be cleaved by SARS-CoV PLP2, and the open triangles mark the sites predicted to be cleaved by SARS-CoV 3CL protease. Numbers 1-16 denode the nsp generated after proteolytic cleavage by SARS-CoV PLP2 or 3CL. The lower panel shows the domain organization of nsp's containing the SARS-CoV PLP2 domain. On this nsp's, Ac, X, SUD, PLP2, Y, and HD stand for the acidic, X, SARS-unique, papain-like protease 2, Y, and hydrophobic domains, respectively (6). The cleavage sites at Gly180-Ala181 (G/A), Gly818-Ala819 (G/A), and Gly2740-Lys2741 (G/K) are marked.

On the basis of sequence comparisons, all coronaviral PLPs, including SARS-CoV PLP2, are thought to be papainlike cysteine proteases with a catalytic dyad composed of Cys and His residues (Figure 2). The sequence homology of the coronaviral PLP domains is less than $25 \%$, and the homology is even lower when compared with papain (14). Therefore, it is not known whether these coronaviral PLPs are similar to cellular papain structurally or catalytically. Mutation at either one of the dyad residues renders the PLPs inactive, as confirmed by its failure to cleave the predicted substrate in vivo in cotransfection studies $(7,12,14,17,19-$ 21). Cys1651 and His 1812 are predicted to be the catalytic dyad residues of SARS-CoV PLP2 $(7,20)$. Mutation to Ala at either site abolishes the activity of SARS-CoV PLP2 (7, 20). In these previous studies, the enzymatic activities associated with coronaviral PLPs, including SARS-CoV PLP2, were demonstrated by the in vivo cotransfection of two plasmids encoding the PLP and substrate polypeptides or by the in vitro transcription and translation of substrate and PLP, followed by Western blot analysis or isotope labeling of the translated polypeptides to detect the cleavage products $(7,9-20,22,23)$. Even though a couple of coronaviral PLP1s have been purified to homogeneity from Escherichia coli cells as either MBP fusion or by itself, their activities were determined on the substrate synthesized and mixed in the reticulocyte lysate $(12,23)$. Whether PLP protease cleaves its substrate unassisted or whether its enzymatic activity requires other cellular components in vivo remains unclear.

Sequence alignment suggests that SARS-CoV PLP2 cleaves the first three sites on pp1a between Gly180 and Ala181, Gly818 and Ala819, and Gly2740 and Lys2741 of SARS-CoV (Figure 1) $(6-8,20)$. An in vitro transcription and translation experiment showed that cleavage most likely occurs at the Gly818-Ala819 sites (7). Furthermore, cleavage products of the predicted sizes were observed in SARSCoV-infected Vero-6 cells and in cotransfection study (20). Although these two recent studies support the proposition that SARS-CoV PLP2 is the enzyme responsible for the cleavages, neither the exact cleavage sites nor the substrate specificity of SARS-CoV PLP2 were investigated. Furthermore, limited information is available on the catalytic properties of coronaviral PLP proteases, possibly because of difficulties in expressing and purifying sufficient amounts of the active protein and the lack of a sensitive and quantitative enzymatic assay with purified enzyme and substrate in vitro. In this study, we purified SARS-CoV PLP2 encoding residues $1414-1858$ out of nsp3 of SARS-CoV from baculovirus-infected insect cells. Reversed-phase highperformance liquid chromatography (RP-HPLC) coupled to mass spectrometry was established to determine its enzymatic activity, substrate specificity, and exact cleavage sites. The catalytic properties were investigated with a steady-state kinetic technique using a fluorogenic substrate. Finally, a fluorescence-based inhibitor-screening platform was designed to screen for the inhibitors of SARS-CoV PLP2.

\section{MATERIALS AND METHODS}

Materials. Grace medium was from Invitrogen. His-Bind Fractogel was from Novagen. Source $15 \mathrm{~S}$ beads and Superdex 200 HR prepacked column were from Amersham Pharmacia. DIG Glycan Differentiation Kit was from Roche. Protease inhibitors were from Sigma. The oligopeptide substrates used in RP-HPLC were synthesized by Kelowna International Scientific (Taiwan).

Plasmid Construction. cDNA encoding a fragment of SARS-CoV PLP2 (amino acids 1414-1858) was PCRamplified from the reverse transcription product of the SARS viral genome (SARS-TW1 strain) with the following primers CGGGATCCTGAACTCTCTAAATGAGCCGC and CGGAATTCTTACGACACAGGCTTGATGGTTG. This region includes the PLP2 activity domain and part of SUD (Figure 1). The BamHI and EcoRI sites in the primers were used to facilitate cloning. The cDNA fragment was cloned into a modified version of the pBacPAK8/His2 vector (24). The resulting plasmid encodes a $51-\mathrm{kDa}$ fusion protein of SARS-CoV PLP2 with a $6 \times$ His tag at its $\mathrm{N}$ terminus. The insert was sequenced to verify cloning.

Insect Cell Culture, DNA Transfection, Virus Selection, and Amplification. Sf9 cells were grown at $27^{\circ} \mathrm{C}$ in Grace medium supplemented with $10 \%$ fetal bovine serum. Transfection of DNA into Sf9 cells and selection and amplification of the recombinant virus were carried out as described previously (24). To express the protein, Sf9 cells were infected at a multiplicity of infection of 3 , and the cells were harvested $48 \mathrm{~h}$ after infection. 


$\begin{array}{lllll}10 & 20 & 30 & 40 & 50\end{array}$

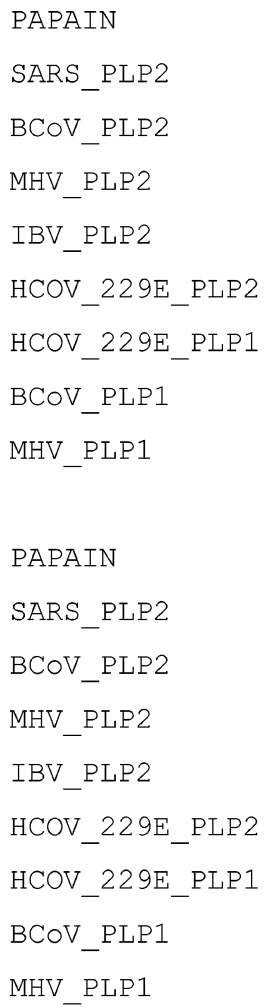

IPEYVDWRQKGAVTPVKNQGSCGSCWAFSAVVTIEGIIKIRTGNLNEYSEQELLDCDR------KWKFPQVGGLT S IKWADNNCYLSSVLLALQQLEVKFN---APALQEAYYRARAGD -----KWQVVFNGKYFT FKQANNNCFVNVSCLMLQSLNLKEK---IVQWQEAWLEFRSGR -----KWPVVVCGNYFAFKQSNNNCY INVACLMLQHLSLKFH---KWQWQEAWNE FRSGK -----KWNVQYRDNFLILEWRDGNCWISSAIVLLQAAKIRFKG----FLTEAWAKLLGGD ------YESAVVNGIRVLKTSDNNCWVNAVCIALQYSKPHFIS---QGLDAAWNKFVLGD -----EMPFEELNGLKILKQLDNNCWVNSVMLQIQLTGILDG-------DYAMQFFKMGR -----EPEFVKVLDLYVPKATRNNCWLRSVLAVMQKLPCQFK---DKNLQDLWVLYKQQY ------ETHFKVCGFYSPAIERTNCWLRSTLIVMQSLPLEFK---DLEMQKLWLSYKSSY

*

RSYGCNGGYPWSALQLVAQYG-IHYRNTYPYEGVQRYCRSREKGPYA------------AANFCALILAYSN--KTVGELGDVRETMTHLLQHANLESAKRVLNVV--CKHCGQKTTTL PARFVSLVLAKGG-FKF-GDPADSRDFLRVVFSQVDLTGAICDFEIA--CK-CGVKQEQR PLRFVSLVLAKGS-FKF-NEPSDSTDFMRVVLREADLSGATCDFEFV--CK-CGVKQEQR PTDFVAWCYASCT-AKV-GDFSDANWLLANLAEHFDADYTNAFLKKRVSCN-CGIKSYEL VEIFVAFVYYVARLMK--GDKGDAEDTLTKLSKYLANEAQVQLEHYS-SCVECDAKFKNS VAKMIERCYTAE--QCIRGAMGDVGLCMYRLLKDLHTGFMVMDYK----CS-CT--SGRL SQLFVDTLVNKI PANIVVPQGGYVADFAYWFLTLCDWQCVAYW-K----CIKCD-LALKL NKEFVDKLVKSVPKSI ILPQGGYVADFAYFFLSQCSFKAYANW-R----CLKCD-MDLKL

TGVEAVMY-MGTLSYDNLKTGVSIPC-VCGRDATQYLVQQESSFVMMSAPP---AEYKLQ TGVDAVMH-FGTLSREDLEIGYTVDC-SCG-KKLIHCVRFDVPFLICSNTP---ASVKLP KGVDAVMH-FGTLDKGDLAKGYTIAC-TCG-NKLVHCTQLNVPFLICSNKP---EGKKLP RGLEACIQPVRATNLLHFKTQYSN-CPTCGANNTDEVIEASLPYLLLFATDG-PATVDCD VASINSAI-VCASVKRDGVQVGY--C-VHGIKYYSRVRSVRGRAIIVSVEQLEPCAQSRL EESGAVLF--CTPTKKAFPYGT---CLNCNAPRMCTIRQLQGTIIFVQQKPEPVNPVSFV KGLDAMFF------YGD-V--VSHVC-KCG-ESMVLIDVDVPFTAHFALKDKLFCAFITK QGLDAMFF------YGD-V--VSHVC-KCG-TGMTLLSADIPYTLHFGLRDDKFCAFYTP

\footnotetext{
LEAAGKDFQLYRGGI FVGPCGNKV--DHAVAAVGYGPNYILIKNS--------WGTGWGENGYIR QGTFLCA---------NEYTGNYQCGHYTHITAKETLYRI--DGAHLTKMSEYKGPVTDVFYKE KG-VGSA---------NIFKG-DKVGHYVHVKCEQSYQLY--DASNVKKVTDVTGNLSDCLYLK DD-V-VA--------ANIFTG-GSLGHYTHVKCKPKYQLY--DACNVSKVSEAKGNFTDCLYLK EDAVGTV----------VFVGSTNSGHCYTQAAGQAFDNLAKDRKFG-KKSPYITAMYTR---LSGVAYT----------AFSGPVDKGHY-TVYDTAKKSMY--DGDRFVKHDLSLLSVTSVVMVG VKPVCSS-----------IFRGAVSCGHYQTNIYSQNLCV---DGFGVNKIQPWTNDALNTICIK RS-VYKA----------ACVVDVNDSHSMAVVDGKQI-----DDHRITSITSDKFDFIIGHGMS RK-VFRA-----------ACVVDVNDCHSMAVVDGKQI-----DGKVVTKFNGDKYDFMVGHGMA
}

FIGURE 2: Alignment of the papain-like domains (PLPs) from papain and coronaviral PLPs. The catalytic dyad residues are marked with an asterisk underneath. Dyad and other conserved residues are marked in bold. The amino acid sequences are from the following Genbank accession numbers: P00784 (papain, amino acids 1-188), AY291451 (SARS-CoV-TW1, amino acids 1632-1847 for PLP2), Q9PYA3 (MHV, amino acids 1050-1251 for PLP1 and 1644-1855 for PLP2), Q66198 (BCoV, amino acids 1055-1257 for PLP1 and 1652-1863 for PLP2), Q05002 (HCoV-229E, amino acids 1035-1239 for PLP1 and 1683-1897 for PLP2), and P27920 (IBV, amino acids $1255-$ 1469), respectively.

Purification and Characterization of SARS-CoV PLP2 Protease. The insect cell pellets were resuspended and sonicated in equilibration buffer containing $20 \mathrm{mM} \mathrm{Na}_{2}-$ $\mathrm{HPO}_{4}-\mathrm{NaH}_{2} \mathrm{PO}_{4}, 0.5 \mathrm{M} \mathrm{NaCl}, 20 \mathrm{mM}$ imidazole, and $7 \mathrm{mM}$ 
$\beta$-mercaptoethanol at $\mathrm{pH}$ 8.0. The cell lysate was cleared by centrifugation at $15000 \mathrm{~g}$ for $15 \mathrm{~min}$ and then loaded onto a His-Bind Fractogel affinity column. The column was washed with equilibration buffer containing $20 \mathrm{mM}$ imidazole then with equilibration buffer containing $90 \mathrm{mM}$ imidazole, before elution with equilibration buffer containing $250 \mathrm{mM}$ imidazole. The buffer of the eluate was changed to buffer A containing $20 \mathrm{mM} \mathrm{Na} 2 \mathrm{HPO}_{4}-\mathrm{NaH}_{2} \mathrm{PO}_{4}$ and $7 \mathrm{mM}$ $\beta$-mercaptoethanol at $\mathrm{pH} 6.2$, using an Amicon Ultra-15 centrifugal filter tube and then loaded onto a Source $15 \mathrm{~S}$ column. The Source $15 \mathrm{~S}$ column was washed with buffer A and then eluted with a gradient of $0-1 \mathrm{M} \mathrm{NaCl}$ in buffer $\mathrm{B}$ containing $20 \mathrm{mM} \mathrm{Na} 2 \mathrm{HPO}_{4}-\mathrm{NaH}_{2} \mathrm{PO}_{4}$ and $7 \mathrm{mM} \beta$-mercaptoethanol at $\mathrm{pH}$ 6.2. Western blot analysis was carried out as described with anti-His antibody from Serotec (U.K.) (25). Gel-filtration chromatography was performed with a Superdex 200 HR column as described previously (26). The stability of PLP2 at different temperatures was studied by incubating the enzyme for $30 \mathrm{~min}$ at various temperatures before determining its initial rate at $37{ }^{\circ} \mathrm{C}$. The enzyme and substrate concentrations used in the reaction were 0.1 and $20 \mu \mathrm{M}$, respectively.

RP-HPLC, Matrix-Assisted Laser Desorption/Ionization Time-of-Flight Mass Spectrometry (MALDI-TOF MS), and Liquid Chromatography Tandem Mass Spectrometry (LC$M S / M S)$. The cleavage reaction included the peptide substrate and the purified SARS-CoV PLP2 enzyme at concentrations of $1 \mathrm{mM}$ and $1 \mu \mathrm{M}$, respectively, in buffer containing 20 $\mathrm{mM} \mathrm{Na} 2 \mathrm{HPO}_{4}-\mathrm{NaH}_{2} \mathrm{PO}_{4}$ and $7 \mathrm{mM} \beta$-mercaptoethanol at $\mathrm{pH}$ 6.8. The reaction was carried out at $37{ }^{\circ} \mathrm{C}$ before the addition of $50 \mu \mathrm{L}$ of $0.1 \%$ trifluoroacetic acid to stop the reaction. The product was analyzed on an Agilent 1100 HPLC system with a Zorbax C18 column $(4.6 \times 250 \mathrm{~mm})$, using a $0-80 \%$ linear gradient of $90 \%$ acetonitrile with $0.1 \%$ trifluoroacetic acid. The cleaved products were collected and analyzed with a Voyager DE-STR Biospectrometry Workstation (PerSpective Biosystems, Framingham, MA). $\alpha-C y-$ ano-4-hydroxycinnamic acid was used as a matrix. For the cleavage products of Gly180-Ala181 oligopeptide, the fraction was further analyzed on a LC-MS/MS system with a Zorbax column $(2.1 \times 250 \mathrm{~mm})$ (LCQ DECA Xpplus, ThermoFinnigan, San Jose, CA), using the same gradient condition in RP-HPLC by replacing trifluoroacetic acid with acetic acid.

Kinetic Constant Measurement. o-Aminobenzoic acid (Abz) and $N$-ethylenediamine-2,4-dinitrophenyl amide (EDDNP) were chosen as the fluorescent donor and quencher (27), respectively, to label the $\mathrm{N}$ and $\mathrm{C}$ termini, respectively, of the peptide substrate FRLKGGAPIKGV, to produce the internally quenched fluorescent substrate Abz-FRLKGGAPIKGV-EDDNP (AnaSpec, San Jose, CA). Enhanced fluorescence emission upon substrate cleavage was monitored at the excitation and emission wavelengths of 320 and 420 nm, respectively (Fluoroskan Ascent, ThermoLabsystems, Sweden). Fluorescence Intensity was converted into amounts of hydrolyzed substrates with a standard curve drawn from the fluorescence measurements of well-defined concentrations of each substrate after complete hydrolysis by SARSCoV PLP2.

The kinetic constants were measured with this fluorogenic peptide substrate or the substrate without the fluorescent label as described previously $(26,28)$. The concentrations of the enzyme and substrate used were $0.1 \mu \mathrm{M}$ and $0.2-3$ times the $K_{\mathrm{m}}$ value $(0.125-1 \mathrm{mM})$, respectively. The buffers used at different $\mathrm{pH}$ values were $20 \mathrm{mM}$ acetate buffer at $\mathrm{pH} 5.25$, $20 \mathrm{mM}$ phosphate buffer at $\mathrm{pH} 6-8,20 \mathrm{mM}$ Tris-HCl buffer at $\mathrm{pH} 8.65$, or $20 \mathrm{mM} 3$-cyclohexylamino-1-propanesulfonic acid (CAPS) at $\mathrm{pH} 9.2-9.8$, all containing $7 \mathrm{mM} \beta$-mercaptoethanol. The change in ionic strength because of the $\mathrm{pH}$ adjustment was negligible with respect to the total ionic strength. Peak area was calculated by integration. The initial rate was measured with less than $10 \%$ substrate depletion for the first 20 min to calculate the kinetic parameters using the Michaelis-Menten equation $(29,30)$. The $\mathrm{pH}-\log k_{\text {cat }}$ or $\mathrm{pH}-\log \left(k_{\mathrm{cat}} / K_{\mathrm{m}}\right)$ profiles were fitted to the following equation for two protonation sites $(29,30)$ :

$$
\log k=\log \frac{C}{1+\frac{\left[\mathrm{H}^{+}\right]}{K_{\mathrm{a} 1}+\frac{K_{\mathrm{a} 2}}{\left[\mathrm{H}^{+}\right]}}}
$$

in which $k$ is the observed kinetic constant $\left(k_{\text {cat }}\right.$ or $\left.k_{\text {cat }} / K_{\mathrm{m}}\right)$ at various $\mathrm{pH}$ values, $C$ is the $\mathrm{pH}$-independent limiting $k$ value, and $K_{\mathrm{a} 1}$ and $K_{\mathrm{a} 2}$ are the macroscopic dissociation constants for the molecular groups responsible for the two ionization steps. All computer-fitted work was performed with the Sigma Plot 5.0 program (Jandel, San Rafael, CA).

Inhibitor-Screening Platform with the Fluorogenic Substrate. An inhibitor-screening platform was set up in a 96well plate containing $50 \mathrm{nM}$ SARS-CoV PLP2 and $20 \mu \mathrm{M}$ fluorogenic substrate Abz-FRLKGGAPIKGV-EDDNP in buffer $\left(20 \mathrm{mM} \mathrm{Na} \mathrm{HPO}_{4}-\mathrm{NaH}_{2} \mathrm{PO}_{4}\right.$ at $\mathrm{pH}$ 6.8) without $\beta$-mercaptoethanol. The enhanced fluorescence emission upon substrate cleavage was monitored at the excitation and emission wavelengths of 320 and $420 \mathrm{~nm}$, respectively, in the presence or absence of the chemical compounds assayed (Fluoroskan Ascent).

\section{RESULTS}

Expression, Purification, and Characterization of SARSCoV PLP2. Because the minimum PLP activity for other coronaviral PLPs was previously identified within a domain of 230-300 residues $(12,19,21,23)$, our construct encodes the region from amino acid 1414 to 1858 of SARS-CoV ppla with a calculated molecular weight of $51 \mathrm{kDa}$. We refer to this region as SARS-CoV PLP2 throughout the text. Whether SARS-CoV PLP2 is glycosylated and whether glycosylation is important for its activity were unknown. Therefore, we chose to express the protein in baculoviral-infected insect cells, which have been used to express glycosylated proteins and other proteins not readily expressible in E. coli cells (31). The purified protease ran approximately at the calculated size of $51 \mathrm{kDa}$ on SDS-PAGE (Figure 3A). In gel-filtration chromatography, the PLP2 was eluted at a position corresponding to a $56.7-\mathrm{kDa}$ protein with a Stokes' radius of 3.3 nm (inset of Figure 3B). The result indicates that purified SARS-CoV PLP2 exists as a monomer in solution. Next, we investigated whether the purified SARS-CoV PLP2 was glycosylated because there are several putative $\mathrm{N}$ - and O-glycosylation sites (data not shown). From DIG Glycan Differentiation Kit (Roche), we detected none of the following glycosylation forms: mannose, $O$-linked disaccharide 

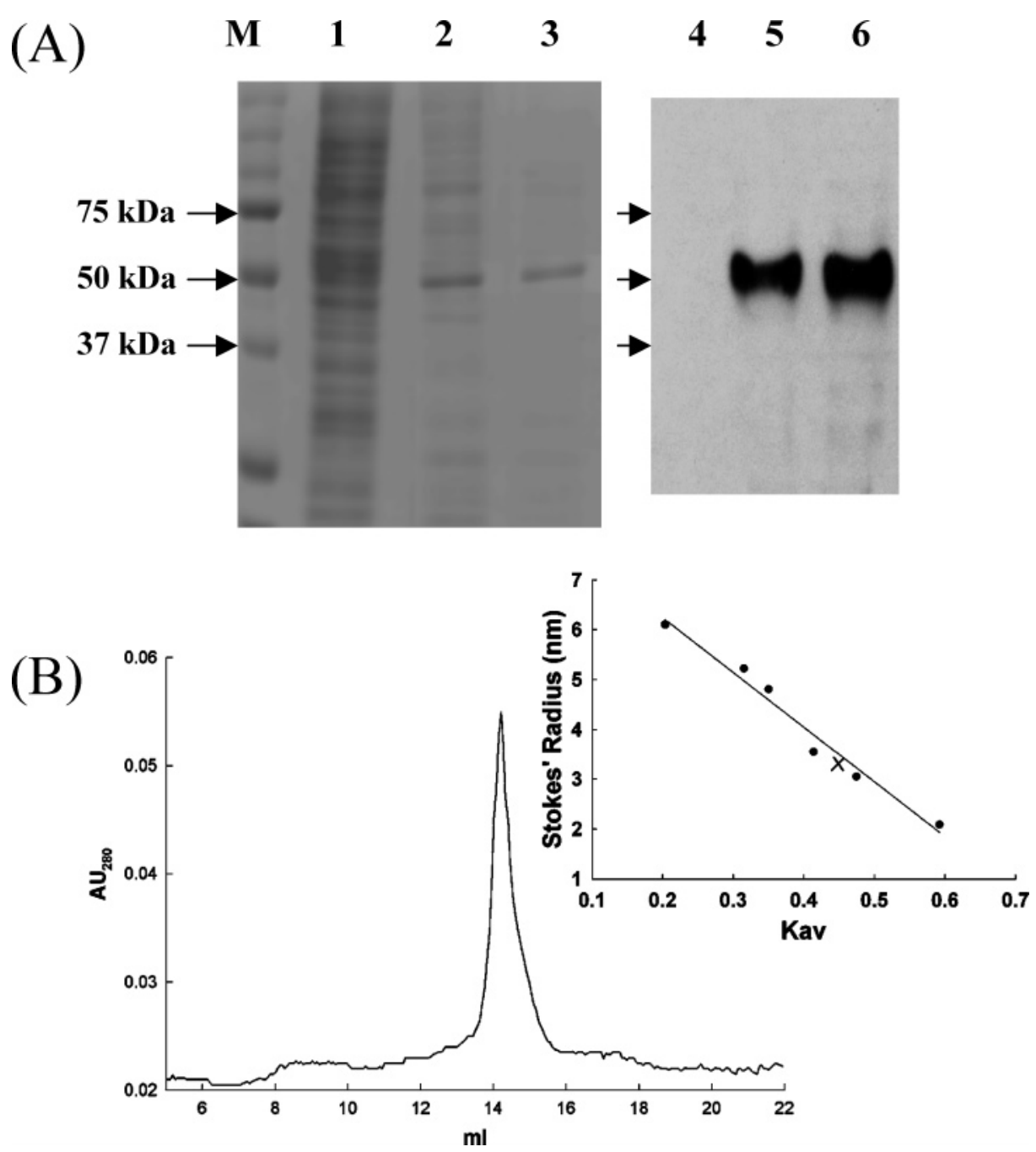

FIGURE 3: Purified SARS-CoV PLP is monomeric. (A) Purification of SARS-CoV PLP2. M indicates the molecular weight markers. Lanes $1-3$ are a Coomassie-blue-stained gel of insect cell lysate, with the eluate from His-Bond Fractogel and the eluate from a Source 15S column, respectively. The amounts of the proteins loaded in lanes 1-3 are 10, 4, and $2 \mu \mathrm{g}$, respectively. Lanes $4-6$ are a Western blot of lanes 1-3, probed with anti-His antibody (see the Materials and Methods). (B) SARS-CoV PLP2 is monomeric by the gel-filtration experiment. The elution profile with a Superdex 200 HR column is shown. The $x$ axis shows the elution position (in milliliters), and the $y$ axis shows the absorbance measurement at $280 \mathrm{~nm}$ to detect the presence of the protein. The inset is the calibration curve for the column. The $\mathrm{X}$ in the inset marks the elution position for SARS-CoV PLP2.

galactose- $\beta(1-3) N$-acetylgalactosamine, $N$-linked galactose- $\beta(1-4)-N$-acetylglucosamine, or $O$-linked $N$-acetylglucosamine (data not shown). Furthermore, the purified PLP2 runs at the expected size on SDS-PAGE (Figure 3A) suggesting that this purified PLP2 is not glycosylated. The activity of the protease was significantly reduced after incubation at temperatures higher than $37^{\circ} \mathrm{C}$ for $30 \mathrm{~min}$ (data not shown), indicating that SARS-CoV PLP2 is inherently thermolabile. This is consistent with the observation that SARS-CoV cannot tolerate high temperatures.

Intrinsic Cleavage Activity of SARS-CoV PLP2. Using the purified SARS-CoV PLP2, we developed an assay method constituted only of enzyme and substrate and analyzed by RP-HPLC and mass spectrometry. The substrates are 12mer oligopeptides containing the predicted Gly180-Ala181, Gly818-Ala819, and Gly2740-Lys2741 cleavage sites, RELNGGAVTRYV, FRLKGGAPIKGV, and ISLKGGKIVSTC, respectively.

As shown in Figure 4A, after 12 h of digestion, only a tiny fraction (5\%) of the Gly180-Ala181 substrate was cleaved. Under the same conditions, cleavage at the Gly818-
Ala819 and Gly2740-Lys2741 sites was 100 and 29\%, respectively (parts $\mathrm{B}$ and $\mathrm{C}$ of Figure 4 ). The percentage cleavage of the Gly818-Ala819 substrate reached $70 \%$ after $2 \mathrm{~h}$ of digestion (Figure 4D). Under the same condition, only $7 \%$ of the Gly2740-Lys2741 sites was cleaved, whereas there was no cleavage detected on the Gly180-Ala181 site (data not shown). All of the peaks in the chromatograms were collected and confirmed by MALDI-TOF MS or LCMS/MS. The mass results unequivocally demonstrated that cleavage occurred at the expected peptide bonds (data not shown). The $12 \mathrm{~h}$ of digestion for the Gly180-Ala181 oligopeptide resulted in a nonspecific cleavage product coeluted with the predicted cleavage product AVTYRV. We only detected the presence of AVTYRV but not RELNGG. These results demonstrated that SARS-CoV PLP2 by itself is active, with a preference for the Gly818-Ala819 site in vitro.

Next, we wanted to determine the requirements for substrate length and composition with oligopeptides ranging from a 6-mer to an 18-mer that encompass the Gly818Ala819 site. The numbering of the $\mathrm{P}-\mathrm{P}^{\prime}$ sites is based on 

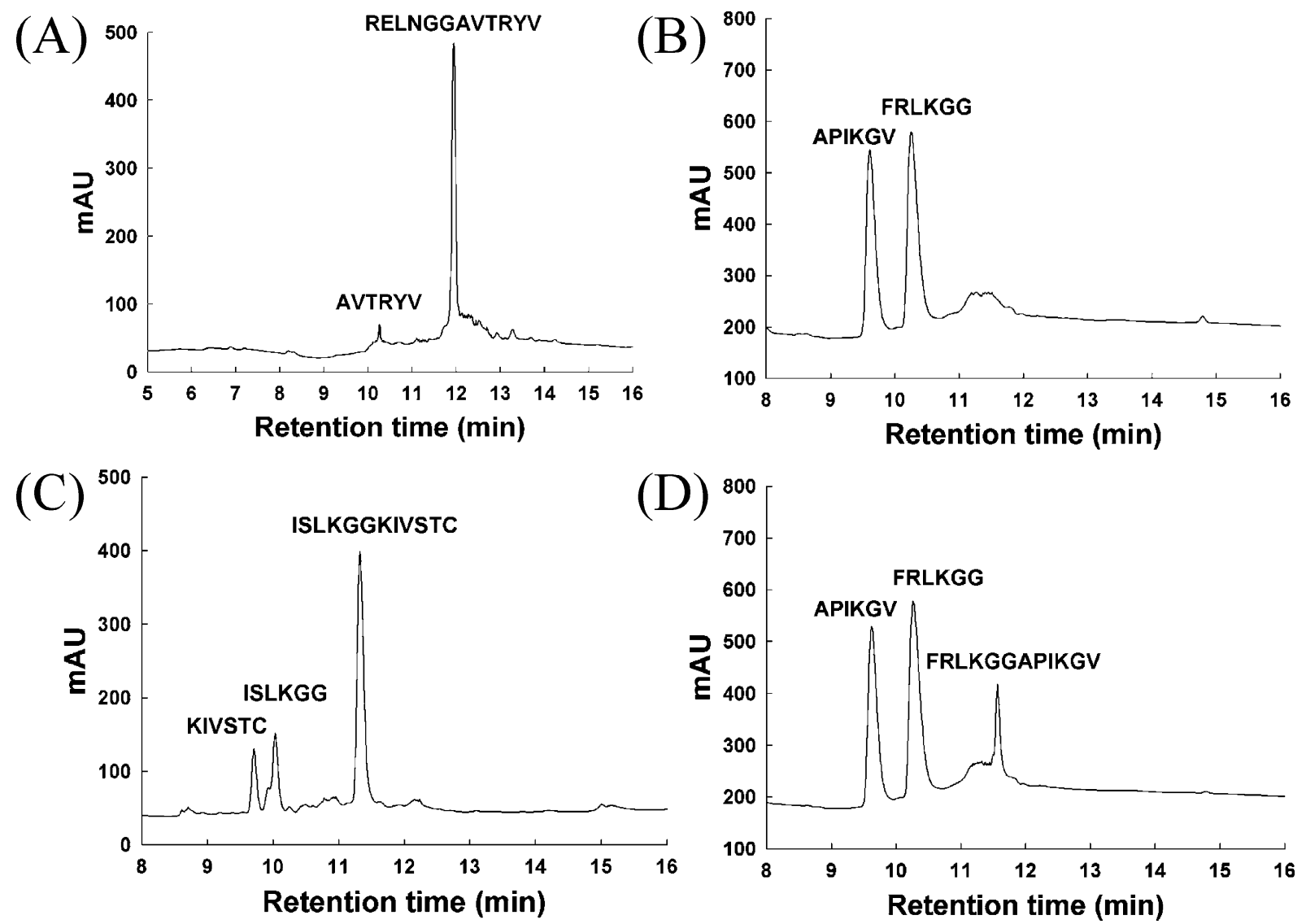

FIGURE 4: RP-HPLC analysis of the sites cleaved by SARS-CoV PLP2. The panels are the HPLC elution profiles of the hydrolyzed products of the oligopeptides RELNGGAVTRYV (A), FRLKGGAPIKGV (B and D), and ISLKGGKIVSTC (C), after incubation with purified SARS-CoV PLP2 for $12(\mathrm{~A}-\mathrm{C})$ or 2 (D) h. The cleavage sites are confirmed by mass spectrometry (data not shown), as indicated on the peaks.

\begin{tabular}{|c|c|c|c|c|c|c|c|c|c|c|c|c|c|c|c|c|c|c|c|c|}
\hline \multirow[b]{2}{*}{ length } & \multicolumn{18}{|c|}{ peptide substrate } & \multicolumn{2}{|c|}{ cleavage $\%^{a}$} \\
\hline & P9 & P8 & $\mathrm{P} 7$ & P6 & P5 & $\mathrm{P} 4$ & P3 & $\mathrm{P} 2$ & $\mathrm{P} 1$ & $\mathrm{P} 1^{\prime}$ & $\mathrm{P} 2^{\prime}$ & P3' & $\mathrm{P} 4^{\prime}$ & $\mathrm{P} 5^{\prime}$ & $\mathrm{P}^{\prime}$ & $\mathrm{P} 7^{\prime}$ & P8' & $\mathrm{P}^{\prime}$ & $2 \mathrm{~h}$ & $12 \mathrm{~h}$ \\
\hline $18^{b}$ & $\mathrm{~N}$ & $\mathrm{~N}$ & $\mathrm{~V}$ & $\mathrm{~F}$ & $\mathrm{R}$ & $\mathrm{L}$ & $\mathrm{K}$ & $\mathrm{G}$ & $\mathrm{G}$ & A & $\mathrm{P}$ & I & $\mathrm{K}$ & $\mathrm{G}$ & $\mathrm{V}$ & $\mathrm{T}$ & $\mathrm{F}$ & $\mathrm{G}$ & $60 \pm 1$ & 100 \\
\hline $16^{b}$ & & $\mathrm{~N}$ & V & $\mathrm{F}$ & $\mathrm{R}$ & $\mathrm{L}$ & $\mathrm{K}$ & G & G & A & $\mathrm{P}$ & I & K & G & V & $\mathrm{T}$ & $\mathrm{F}$ & & $63 \pm 1$ & 100 \\
\hline 14 & & & $\mathrm{~V}$ & $\mathrm{~F}$ & $\mathrm{R}$ & $\mathrm{L}$ & $\mathrm{K}$ & $\mathrm{G}$ & $\mathrm{G}$ & A & $\mathrm{P}$ & I & K & $\mathrm{G}$ & $\mathrm{V}$ & $\mathrm{T}$ & & & $68 \pm 9$ & 100 \\
\hline 12 & & & & $\mathrm{~F}$ & $\mathrm{R}$ & $\mathrm{L}$ & $\mathrm{K}$ & $\mathrm{G}$ & G & A & $\mathrm{P}$ & I & K & G & V & & & & $70 \pm 7$ & 100 \\
\hline 11 & & & V & $\mathrm{F}$ & $\mathrm{R}$ & $\mathrm{L}$ & K & G & G & A & $\mathrm{P}$ & I & K & & & & & & $53 \pm 4$ & 100 \\
\hline 10 & & & & $\mathrm{~F}$ & $\mathrm{R}$ & $\mathrm{L}$ & K & G & G & A & $\mathrm{P}$ & I & K & & & & & & $50 \pm 3$ & 100 \\
\hline 10 & & & & & $\mathrm{R}$ & $\mathrm{L}$ & $\mathrm{K}$ & G & $\mathrm{G}$ & A & $\mathrm{P}$ & I & K & G & & & & & $15 \pm 4$ & $56 \pm 6$ \\
\hline 9 & & & & $\mathrm{~F}$ & $\mathrm{R}$ & $\mathrm{L}$ & $\mathrm{K}$ & G & $\mathrm{G}$ & A & $\mathrm{P}$ & I & & & & & & & $36 \pm 6$ & $85 \pm 5$ \\
\hline 8 & & & & & & $\mathrm{~L}$ & $\mathrm{~K}$ & G & G & A & $\mathrm{P}$ & I & $\mathrm{K}$ & & & & & & $11 \pm 4$ & $45 \pm 4$ \\
\hline 6 & & & & & & & $\mathrm{~K}$ & G & $\mathrm{G}$ & A & $\mathrm{P}$ & I & & & & & & & $\mathrm{nd}^{c}$ & nd \\
\hline
\end{tabular}

${ }^{a}$ Percentages of the cleavage is the average of three independent measurements using three different batches of enzyme. ${ }^{b}$ Because of their low solubility, $0.5 \mathrm{mM}$, instead of $1 \mathrm{mM}$, of the 18 - and 16-mer oligopeptides were used in the assay. ${ }^{c}$ Cleavage was not detectable.

Berger and Schechter, with cleavage occurring between the $\mathrm{P} 1$ and $\mathrm{P} 1{ }^{\prime}$ sites (Table 1) (32). As shown in Table 1, oligopeptides ranging from a 10-mer to an 18-mer, including a 10-mer with six residues in the $P$ positions and four in the $\mathrm{P}^{\prime}$ sites, i.e., FRLKGG-APIK, were excellent substrates for cleavage and were over 50 and $100 \%$ cleaved, respectively, after 2 and $12 \mathrm{~h}$ of digestion. Interestingly, the 10-mer oligopeptide with five residues at both the $\mathrm{P}$ and $\mathrm{P}^{\prime}$ sites, RLKGG-APIKG, was not efficiently cleaved, with only $56 \%$ cleavage after $12 \mathrm{~h}$ of incubation (Table 1). Moreover, a 9-mer with six residues in the $\mathrm{P}$ sites and three residues in the P' sites, FRLKGG-API, was a much better substrate than the 10-mer with five residues in the P sites. This 9-mer was 36 and $85 \%$ cleaved after 2 and $12 \mathrm{~h}$ of digestion, respectively (Table 1). These results indicate that six residues in the $\mathrm{P}$ sites are critical for efficient recognition and cleavage by the enzyme. Consistent with this, shorter oligopeptides (8- and 6-mer) lacking the P6 residue were poorly cleaved. For the 8 -mer peptide, 11 and $45 \%$ were cleaved after 2 and $12 \mathrm{~h}$, respectively, while there was no cleavage at all for the 6-mer (Table 1). Therefore, the P6 residue seems to contribute significantly to substrate recognition and cleavage by SARS-CoV PLP2.

Catalytic Properties of SARS-CoV PLP2. The kinetic constants were determined for the optimal substrate Gly818Ala819, FRLKGGAPIKGV. The apparent $k_{\text {cat }}$ and $K_{\mathrm{m}}$ values were $1.5 \mathrm{~min}^{-1}$ and $185 \mu \mathrm{M}$, respectively. We then designed a fluorogenic substrate, Abz-FRLKGGAPIKGV-EDDNP, 
Table 2: Kinetic Parameters of SARS-CoV PLP2 at Different pH Values $^{a}$

\begin{tabular}{crcc}
\hline $\mathrm{pH}$ & $k_{\mathrm{cat}}\left(\mathrm{min}^{-1}\right)$ & $K_{\mathrm{m}}(\mu \mathrm{M})$ & $k_{\mathrm{cat}} / K_{\mathrm{m}}\left(\mu \mathrm{M}^{-1} \min ^{-1}\right)$ \\
\hline 5.25 & $1.4 \pm 0.2$ & $21.4 \pm 1.1$ & $0.06 \pm 0.01$ \\
6.05 & $11.9 \pm 1.1$ & $64.0 \pm 0.3$ & $0.17 \pm 0.03$ \\
6.82 & $20.6 \pm 2.4$ & $65.4 \pm 5.4$ & $0.31 \pm 0.01$ \\
7.42 & $19.8 \pm 2.3$ & $77.2 \pm 2.1$ & $0.27 \pm 0.03$ \\
8.01 & $21.8 \pm 1.8$ & $72.0 \pm 4.3$ & $0.30 \pm 0.02$ \\
8.65 & $22.0 \pm 3.1$ & $71.4 \pm 8.0$ & $0.30 \pm 0.01$ \\
9.20 & $14.0 \pm 0.5$ & $68.0 \pm 0.6$ & $0.21 \pm 0.02$ \\
9.80 & $6.0 \pm 0.4$ & $70.4 \pm 1.5$ & $0.08 \pm 0.01$ \\
\hline
\end{tabular}

${ }^{a}$ Kinetic constants were measured as described in the Materials and Methods.

which has little fluorescent emission because of the fluorescence resonance energy transfer (FRET) between Abz and EDDNP (27). When this peptide substrate is cleaved between the Gly and Ala by SARS-CoV PLP2, the FRET disappears and fluorescence intensity increases (27). The apparent $k_{\text {cat }}$ and $K_{\mathrm{m}}$ values for this fluorogenic substrate at $\mathrm{pH} 7.4$ were $20 \pm 2 \mathrm{~min}^{-1}$ and $77 \pm 2 \mu \mathrm{M}$, respectively (Table 2). Using fluorescent substrate is a much more sensitive and convenient method for determination of the enzymatic property, as observed before for other proteases (33). From this method, we determined the $k_{\text {cat }}$ and $K_{\mathrm{m}}$ values of the enzyme at different $\mathrm{pH}$ values ranging from $\mathrm{pH} 5.25$ to 9.8. As shown in Table 2, the enzymatic activity of SARS-CoV PLP2 $\left(k_{\text {cat }}\right)$ $K_{\mathrm{m}}$ values) was optimal at $\mathrm{pH} 6.8-8.6$. Lowering the $\mathrm{pH}$ to 5.25 affected both the $K_{\mathrm{m}}$ and $k_{\text {cat }}$ values, with a more significant effect on $k_{\text {cat }}$. The $k_{\text {cat }}$ value decreased almost 15fold, whereas there was only a 3 -fold increment in the $K_{\mathrm{m}}$ value. At $\mathrm{pH} 9.8$, there was a 3 -fold decrease in $k_{\text {cat }}$, with no effect on $K_{\mathrm{m}}$ (Table 2). These results indicate that the activity of SARS-CoV PLP2 is greatly modulated by $\mathrm{pH}$, reflecting the stability of the thiolate-imidazolium ion pair at different $\mathrm{pH}$ values.

These kinetic data were further analyzed by fitting them to an equation involving the two protonation forms (see the Materials and Methods). Both the catalytic constant $\left(k_{\text {cat }}\right)$ and the specificity constant $\left(k_{\text {cat }} / K_{\mathrm{m}}\right)$ of the enzyme displayed bellshaped activity versus $\mathrm{pH}$ dependence, consistent with the existence of two macroscopic molecular ionizable groups associated with maximal catalysis (Figure 5). The apparent $\mathrm{p} K_{\mathrm{a}}$ values for these ionizable residues were obtained with an excellent fit in both cases. From the $\mathrm{pH}-\log k_{\text {cat }}$ plot, a constant $C$ value of $25 \pm 3 \mathrm{~min}^{-1}$, equivalent to the $\mathrm{pH}$ independent $k_{\text {cat }}$ value, was obtained. This is the true $k_{\text {cat }}$ value, higher than the apparent value $\left(20 \pm 2 \mathrm{~min}^{-1}\right)$ determined in the regular assay at a fixed $\mathrm{pH}$ of 7.4 (Table 2 ). From the $\mathrm{pH}-\log k_{\mathrm{cat}}$ plot, two macroscopic molecular $\mathrm{p} K_{\mathrm{a}}$ values of $6.4 \pm 0.1$ and $9.3 \pm 0.2$ were obtained, most likely attributable to the dyad residues Cys1651 and His 1812 of SARS-CoV PLP2. These results indicate that these two residues form the ion pair involved in the catalytic step of enzymatic catalysis and that the enzymatic activity is modulated electrostatically for catalytic competence. These data are consistent with the characteristics of a papain-like cysteine protease $(34,35)$.

From the $\mathrm{pH}-\log \left(k_{\text {cat }} / K_{\mathrm{m}}\right)$ plot, a constant $C$ value of 0.3 $\pm 0.02 \mathrm{~min}^{-1} \mu \mathrm{M}^{-1}$, equivalent to the $\mathrm{pH}$-independent $k_{\text {cat }} /$ $K_{\mathrm{m}}$ value, was obtained. This is the true $k_{\text {cat }} / K_{\mathrm{m}}$ value and is the same as that determined in the regular assay at a fixed
(A)

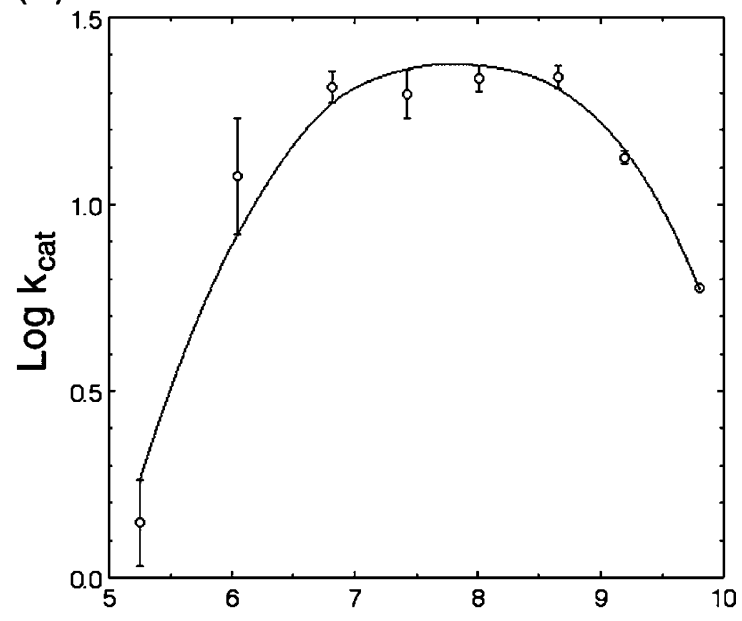

(B) $\quad \mathrm{pH}$

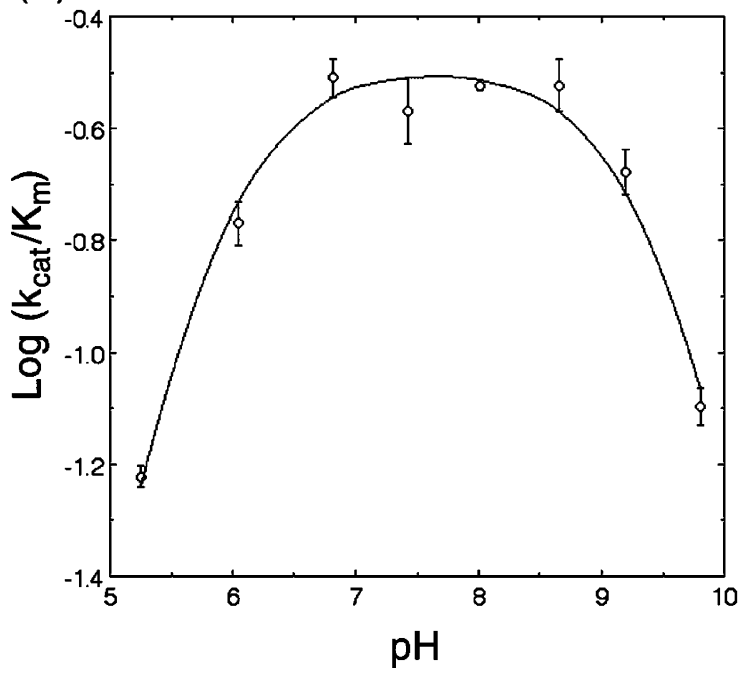

FIGURE 5: Dependence of the kinetic parameters of SARS-CoV PLP2 on pH. (A) Dependence of the catalytic constant $\left(k_{\text {cat }}\right)$ of SARS-CoV PLP2 on pH. (B) Dependence of the specificity constant $\left(k_{\mathrm{cat}} / K_{\mathrm{m}}\right)$ of SARS-CoV PLP2 on $\mathrm{pH}$. In both panels, open circles show the data from the kinetic experiments. The line is the computer-generated result of fitting the experimental data shown in Table 2 to an equation for two ionizable groups (see the Materials and Methods).

$\mathrm{pH}$ of 7.4 (Table 2). Therefore, the true $K_{\mathrm{m}}$ value for the 12 -mer peptide substrate should be corrected to $82 \mu \mathrm{M}$. Two apparent $\mathrm{p} K_{\mathrm{a}}$ values of $5.9 \pm 0.1$ and $9.4 \pm 0.1$ were obtained from the $\mathrm{pH}-\log \left(k_{\mathrm{cat}} / K_{\mathrm{m}}\right)$ plot. The former must be deprotonated, and the latter must be protonated to achieve an optimal substrate-binding mode. At this stage, identification of these macroscopic molecular groups, in terms of specific amino acid residues, is not straightforward.

Substrate Specificity of SARS-CoV PLP2. We then investigated the substrate specificity of SARS-CoV PLP2 by focusing on the P6 to P1' sites, because the corresponding residues in other coronaviral PLPs affect the cleavages as shown before $(11,21,22,36,37)$ and in this study (Table 1). The optimal substrate Gly818-Ala819 was used for comparison. As shown in Table 3, substitution at either the P1 (Gly) or P4 (Leu) position with Ala or Lys (G818A, L815A, or L815K) was not tolerated at all, with no cleavage observed after $12 \mathrm{~h}$ of digestion. A significant decrease in cleavage, from 70 to around $20 \%$ after $2 \mathrm{~h}$, or from 100 to around $50 \%$ after $12 \mathrm{~h}$, was observed when the P2 (Gly) or 
Table 3: Substrate Specificity of SARS-CoV PLP2

\begin{tabular}{|c|c|c|c|c|c|c|c|c|c|}
\hline \multirow[b]{2}{*}{ source } & \multicolumn{7}{|c|}{ peptide substrate $^{a}$} & \multicolumn{2}{|c|}{ cleavage $\%^{b}$} \\
\hline & P6 & P5 & $\mathrm{P} 4$ & P3 & $\mathrm{P} 2$ & $\mathrm{P} 1$ & $\overline{\mathrm{P} 1^{\prime}}$ & $2 \mathrm{~h}$ & $12 \mathrm{~h}$ \\
\hline Gly818-Ala819 & $\mathrm{F}$ & $\mathrm{R}$ & $\mathrm{L}$ & K & G & G & A & $70 \pm 7$ & 100 \\
\hline A819G & & & & & & & G & $65 \pm 10$ & 100 \\
\hline A819N & & & & & & & $\mathrm{N}$ & $62 \pm 12$ & 100 \\
\hline G818A & & & & & & A & & $\mathrm{nd}^{c}$ & nd \\
\hline G817A & & & & & A & & & $16 \pm 3$ & $46 \pm 7$ \\
\hline G816A & & & & A & & & & $71 \pm 10$ & 100 \\
\hline G816Q & & & & Q & & & & $58 \pm 8$ & 100 \\
\hline L815A & & & A & & & & & nd & nd \\
\hline L815K & & & $\mathrm{K}$ & & & & & nd & nd \\
\hline R814A & & A & & & & & & $32 \pm 6$ & $82 \pm 3$ \\
\hline R814S & & $\mathrm{S}$ & & & & & & $33 \pm 5$ & $85 \pm 2$ \\
\hline F813A & A & & & & & & & $17 \pm 2$ & $56 \pm 5$ \\
\hline F813V & V & & & & & & & $20 \pm 5$ & $64 \pm 7$ \\
\hline
\end{tabular}

${ }^{a}$ The substrates used in the study were all 12-mers. Only the P6$\mathrm{P} 1^{\prime}$ sites are shown. Substitutions were as indicated. The other sites (not shown) are the same as in the original Gly818-Ala819 oligopeptide FRLKGGAPIKGV. ${ }^{b}$ Percentage cleavage is the average of three independent measurements using three different batches of enzyme. ${ }^{c}$ Cleavage is not detectable.

Table 4: Summary of the Substrates of Some Coronaviral PLPs

\begin{tabular}{lrllllllllll}
\hline & \multicolumn{1}{c}{ veptide substrate } & & & \\
\cline { 2 - 7 } \multicolumn{1}{c}{ virus } & AA $^{b}$ & P6 & P5 & P4 & P3 & P2 & P1 & P1' & protease $^{c}$ & references \\
\hline SARS-CoV & 175 & R & E & L & N & G & G & A & PLP2 & this paper \\
SARS-CoV & 813 & F & R & L & K & G & G & A & PLP2 & this paper \\
SARS-CoV & 2735 & I & S & L & K & G & G & K & PLP2 & this paper \\
MHV & 2832 & F & S & L & K & G & G & A & PLP2 & 22 \\
BCoV & 2745 & F & S & L & K & G & G & A & PLP2 & 38 \\
HCoV-229E & 892 & F & T & K & A & A & G & G & PLP1/2 & 14 \\
IBV & 668 & V & V & C & K & A & G & G & PLP2 & 15 \\
IBV & 2260 & V & E & K & K & A & G & G & PLP2 & 16 \\
MHV & 242 & L & K & G & Y & R & G & V & PLP1 & 36,37 \\
MHV & 827 & W & R & F & P & C & A & G & PLP1 & 11 \\
BCoV & 241 & I & R & G & Y & R & G & V & PLP1? & 38 \\
BCoV & 846 & W & R & V & P & C & A & G & PLP1? & 38 \\
HCoV-229E & 106 & G & K & R & G & G & G & N & PLP1 & 12 \\
HCoV-229E & 892 & F & T & K & A & A & G & G & PLP1/2 & 14 \\
\hline
\end{tabular}

${ }^{a}$ Genbank accession numbers are AY291451 (SARS-CoV-TW1), Q9PYA3 (MHV), Q66198 (BCoV), Q05002 (HCoV-229E), and P27920 (IBV), respectively. The horizontal line separates the coronaviral PLP2s from PLP1s. ${ }^{b}$ The starting position of the amino acid corresponds to the P6 site. ${ }^{c}$ The question mark denotes unknown or unconfirmed information.

P6 (Phe) position was substituted with Ala or Val (G817A, F813A, or F813V) (Table 3). The substitution of P5 (Arg) with either Ala or Ser (R814A or R814S) resulted in moderately reduced cleavage, whereas substitution of $\mathrm{P} 3$ (Lys) with either Ala or Gln (K816A and K816Q) did not affect cleavage at all. Furthermore, substitution at the $\mathrm{P} 1^{\prime}$ (Ala) position with either Gly or Asn (A819G and A819N) did not affect cleavage at all. Therefore, the P1, P2, P4, and P6 positions are important for optimal substrate recognition and cleavage by SARS-CoV PLP2, also consistent with the observation presented in Table 1.

Cleavage of the MHV and BCoV Substrates by SARS-CoV $P L P 2$. The amino acid sequences are poorly conserved among the confirmed sites of cleavage by coronaviral PLP1s from MHV and HCoV-229E, except that the P1 site is either Gly or Ala (Table 4). Interestingly, we identified a consensus cleavage motif by coronaviral PLP2s, quite different from those recognized by PLP1s. SARS-CoV and MHV PLP2s share the consensus motif F/I-R/S-L-K-G-G from position
Table 5: SARS-CoV PLP2 Cleaves the Substrates of MHV and $\mathrm{BCoV}$

\begin{tabular}{|c|c|c|c|c|c|c|c|c|c|}
\hline \multirow[b]{2}{*}{ source } & \multicolumn{7}{|c|}{ peptide substrate ${ }^{a}$} & \multicolumn{2}{|c|}{ cleavage $\%^{b}$} \\
\hline & P6 & P5 & $\mathrm{P} 4$ & $\mathrm{P} 3$ & $\mathrm{P} 2$ & $\mathrm{P} 1$ & $\overline{\mathrm{P} 1^{\prime}}$ & $2 \mathrm{~h}$ & $12 \mathrm{~h}$ \\
\hline ly180- & $\mathrm{R}$ & E & $\mathrm{L}$ & $\mathrm{N}$ & $\mathrm{G}$ & $\mathrm{G}$ & A & $\mathrm{nd}^{c}$ & $5 \pm$ \\
\hline Gly818-A & $\mathrm{F}$ & $\mathrm{R}$ & $\mathrm{L}$ & $\mathrm{K}$ & G & $\mathrm{G}$ & A & $70 \pm 7$ & 100 \\
\hline Gly $2740-\mathrm{L}$ & I & $\mathrm{S}$ & $\mathrm{L}$ & $\mathrm{K}$ & $\mathrm{G}$ & $\mathrm{G}$ & $\mathrm{K}$ & & $29 \pm$ \\
\hline HV & $\mathrm{F}$ & $\mathrm{S}$ & $\mathrm{L}$ & $\mathrm{K}$ & G & $\mathrm{G}$ & A & & $80=$ \\
\hline $\mathrm{Co}$ & $\mathrm{F}$ & $\mathrm{S}$ & $\mathrm{L}$ & $\mathrm{K}$ & G & $\mathrm{G}$ & A & $27 \pm 4$ & $85 \pm$ \\
\hline CoV-229E & $\mathrm{F}$ & $\mathrm{T}$ & $\mathrm{K}$ & A & A & $\mathrm{G}$ & $\mathrm{G}$ & nd & nd \\
\hline IBV & $\mathrm{V}$ & $\mathrm{E}$ & $\mathrm{K}$ & $\mathrm{K}$ & A & $\mathrm{G}$ & G & nd & nd \\
\hline
\end{tabular}

${ }^{a}$ The substrates used in the study were all 12-mers. Only positions P6-P1' are shown. The sequences have the following GenBank accession numbers: AY291451 (SARS-CoV-TW1), Q9PYA3 (MHV), Q66198 (BCoV), Q05002 (HCoV-229E), and P27920 (IBV). ${ }^{b}$ Percentage cleavage is the average of three independent measurements using three different batches of enzyme. ${ }^{c}$ Cleavage was not detectable.

P6 to P1, while PLP2s from HCoV-229E and IBV share the conserved motif A-G-G at the corresponding $\mathrm{P} 2-\mathrm{P} 1-\mathrm{P} 1^{\prime}$ positions, with the residues at the remaining positions divergent (Table 4). Notably, one of the sites in $\mathrm{BCoV}$ predicted to be cleaved by its PLP has the sequence F-S-LK-G-G from position P6 to P1 (38), matching the consensus sequence of F/I-R/S-L-K-G-G postulated in this study (Table 4). We were interested to know whether SARS-CoV PLP2 cleaves these homologous sites of MHV and BCoV.

At least $80 \%$ of the MHV or BCoV substrate was cleaved in a $12 \mathrm{~h}$ incubation, compared with $100 \%$ cleavage at the Gly818-Ala819 site of SARS-CoV (Table 5). These two substrates from $\mathrm{MHV}$ and $\mathrm{BCoV}$ were even better in vitro than the other two sites of SARS-CoV, Gly180-Ala181 and Gly2740-Lys2741. After 2 h of digestion, SARS-CoV PLP2 cleaved about 21 and $27 \%$ of the MHV and BCoV substrates, respectively, whereas it cleaved only $7 \%$ of its own Gly2740-Lys2741 site and did not cleave the Gly180Ala181 site at all (Table 5). Furthermore, SARS-CoV PLP2 did not cleave the sites from HCoV-229E and IBV even after $12 \mathrm{~h}$ of digestion (Table 5). Therefore, SARS-CoV PLP2 shares substrate homology with those of MHV and $\mathrm{BCoV}$, and it cleaves these homologous substrates from them. The epidemiological and evolutionary implications of these results are discussed below.

An Effective Inhibitor of SARS-CoV PLP2 by InhibitorScreening Platform. We designed a fluorogenic inhibitorscreening platform using only nanomolar amounts of SARSCoV PLP2, which is suitable for adaptation to high throughput screening. Interestingly, zinc ion inhibited the protease activity potently with the $\mathrm{IC}_{50}$ value of $1.3 \mu \mathrm{M}$ (data not shown). Zinc conjugates, including $N$-ethyl- $N$-phenyldithiocarbamic acid $\mathrm{Zn}$ and hydroxypridine-2-thione $\mathrm{Zn}$ were also effective in inhibiting SARS-CoV PLP2, with the $\mathrm{IC}_{50}$ values of 3.3 and $3.7 \mu \mathrm{M}$, respectively. The inhibition is specific because other divalent metals, such as $\mathrm{Mg}, \mathrm{Mn}, \mathrm{Ca}, \mathrm{Ni}$, and $\mathrm{Co}$, had no effects on the activity of SARS-CoV PLP2 at 10 $\mu \mathrm{M}$ (data not shown). $\mathrm{Cu}$ ion at $10 \mu \mathrm{M}$ weakly inhibited the activity of the PLP2 to 70\% (data not shown). Although the mechanism of this inhibition by zinc is not yet understood, we used this as a control to investigate the inhibitory effects of some commercially available and known cysteine protease inhibitors. None of the known cysteine protease inhibitors, including E64 at $0.1 \mathrm{mM}, N$-ethylmaleimide at $1 \mathrm{mM}$, 
cystatin at $10 \mu \mathrm{g} / \mathrm{mL}$, leupeptin at $0.1 \mathrm{mM}$, antipain at 0.1 $\mathrm{mM}$, and chymostatin at $1 \mathrm{mM}$, were effective in inhibiting SARS-CoV PLP2 (data not shown). These results suggest that the catalytic dyad of SARS-CoV PLP2 is not readily accessible to these inhibitory compounds, and zinc ion is an effective inhibitor of SARS-CoV PLP2.

\section{DISCUSSION}

The controlled proteolysis of the replicase polypeptides by viral proteases is essential for viral virulence and biogenesis. In this study, we demonstrated that, despite low sequence homology (Figure 2), SARS-CoV PLP2 catalytically is a "papain-like" enzyme with simlar catalytic mechanism as that of papain, providing the first clue on the reaction mechanism of SARS-CoV PLP2. Catalytically, SARS-CoV PLP2 is different from cathepsins, papain-like cysteine proteases also belonging to the papain superfamily but with a narrow acidic $\mathrm{pH}$ optima $(39,40)$. It will be interesting to determine whether other coronaviral PLPs share similar enzymatic properties with SARS-CoV PLP2. Even though the catalytic dyad is ubiquitously present among coronaviral PLPs and papain $(34,35,41-43)$, the residues around the Cys and His dyad are quite different (Figure 2). The nucleophilic Cys is preceded by Asn and followed by a hydrophobic (Y, F, or W) residue in coronaviral PLPs, while there is a signiture motif GSCWAFS at the Cys active site of papain. In coronaviral PLPs, the dyad residue His is preceded by a Gly (or Cys and Ser for PLP1s of BCoV and MHV, respectively) and followed by several hydrophobic residues, while Asp precedes the active-site His of papain. Structurally, acidic groups nearby the dyad might contribute electrostatically to the modulation of the catalytically competent dyad ion pair $\left(\mathrm{Cys}-\mathrm{His}^{+}\right)(34)$. The wide $\mathrm{pH}-$ activity profiles indicate that this ionized thiolate-imidazolium ion pair is relatively more stable than is its neutral form (35). PLP2s from both MHV and SARS-CoV are not inhibited by most commonly used cysteine protease inhibitors (see ref 13 and this study). In contrast, PLP1 from MHV is sensitive to these inhibitors, as shown by transfection studies $(13,19,37,44,45)$. These data suggest that the substratebinding sites or the environments of the catalytic dyad in coronaviral PLP2s might be different significantly from those in PLP1s or other E64-sensitive cysteine proteases, raising a possibility that structurally PLP1s might differ from their PLP2 counterparts.

We demonstrate that SARS-CoV PLP2 by itself is active, independent of contributions from the cellular environment or other cellular factors. Mass spectrometry to determine the cleavage site is a sensitive alternative compared to the previously used method $(14,36,46)$. Employing the method of HPLC coupled with mass spectrometry, we not only confirm without a doubt the cleavage sites by SARS-CoV PLP2 but also detect the enzymatic activity of SARS-CoV not observable in vivo as described in Hartcourt et al. (20). In our study, cleavage at the Gly2740-Lys2741 site was detected by RP-HPLC (Figure 4C), although it was not detected in an in vivo study with a slightly longer PLP2 (residues 1540-2204) (20). Only when the C-terminal region was extended to include a hydrophobic domain (residues 1540-2425) did cleavage of this Gly2740-Lys2741 site occur in vivo (20). Our study shows that the intrinsic activity of SARS-CoV PLP2 can process all three predicted sites with differential activity and that the extent of cleavage differs from that observed in the in vivo study (20). Purified SARSCoV PLP2 marginally cleaved the Gly180-Ala181 site in vitro, with the greatest activity observed at the Gly818Ala819 site (Figure 4 and Table 5). However, the Gly180Ala181 site was readily cleaved in vivo, seemingly with the greatest efficiency, whereas the other two sites, Gly818Ala819 and Gly2740-Lys2741, were less efficiently processed (20). The different results in vitro (this study) and in vivo (20) are explainable because previous studies on other coronaviral PLPs have shown that the length and boundary of PLP domains affect the efficiency of the cleavage on the substrates in vivo $(14,23)$. Thus, the region outside the activity domain and/or the cellular localization of SARSCoV PLP2 contributes to its activity observed in vivo.

SARS-CoV PLP2 is capable of cleaving the PLP2 substrate sites from MHV and $\mathrm{BCoV}$ but not those from HCoV-229E and IBV (Table 5). Accordingly, we speculate that the site from BCoV, FSLKGGA, is cleaved by its PLP2 rather than by its PLP1 (Table 5). On the basis of the common properties shared with MHV and $\mathrm{BCoV}$ on substrate homology and cleavage and insensitivity to E64, our study supports that SARS-CoV diverges early in evolution from MHV and $\mathrm{BCoV}(6,47)$. Therefore, rather than classifying SARS-CoV as an independent group 4 as originally proposed $(3,4)$, our data provide evidence to classify SARS-CoV phylogenetically as group $2 \mathrm{~b}$ relative to group $2 \mathrm{a}$, which includes MHV and $\mathrm{BCoV}(6,47)$. Supporting this, both viral proteins and RNA in the replicative machinery of MHV and SARS-CoV are similarly located in the membrane compartment in vivo, as demonstrated by electron microscopy and immunostaining experiments $(20,48-50)$. The information provided in this study is important for SARS-CoV-related research and epidemiology because it validates the use of MHV (and $\mathrm{BCoV}$ ) as a suitable model with which to characterize SARS-CoV genes/proteins and functions (47).

Different from MHV PLP2 (22) and uniquely for SARSCoV PLP2, P4 (Leu) is critical for substrate recognition and cleavage (Table 3 ). In addition, the P6 site might contribute through anchoring of the substrate to the active site (Table 1). Thus, it is likely that the peptidomimetic compound with a longer chain might work as an inhibitor to inhibit the enzymatic activities. Importantly, we found that SARS-CoV PLP2 is the molecular target for zinc inhibition. Because none of the structures of coronaviral PLPs is available, how the high concentration of zinc ion affects the activity of SARS-CoV PLP2 awaits further study. It is interesting to note that zincum gluconicum (Zenullose or ZICAM sold over the counter), a zinc salt and a homeopathic therapy, is effective in treating the common cold, a disease caused by rhinoviruses, although its molecular target is not yet known (51). In addition, zinc acetate is added as a supplement for the treatement of Wilson's disease, indicating that zinc is safe to use in humans (52). Previously, zinc and some zinc conjugates are found to be effective inhibitors for SARSCoV 3CL protease (53). Therefore, using high dosage of zinc or zinc conjugates might be effective for inhibiting SARS$\mathrm{CoV}$ replication in vivo through the simultaneous inhibition of SARS-CoV PLP2 and 3CL protease. Our detailed study of substrate preference and fluorogenic inhibitor-screening platform will also assist in the design and discovery of novel pharmacophores specific for PLP2 inhibition. 


\section{ACKNOWLEDGMENT}

We are very grateful to Drs. Yi-Ling Lin, Li-Jung Luan, Martin Renatus, Chun Wang, and Peter Rubenstein for critically reading the manuscript and making suggestions. We also thank Drs. Po-Huang Liang and Shih-Feng Tsai for their help.

\section{REFERENCES}

1. Peiris, J. S., Chu, C. M., Cheng, V. C., Chan, K. S., Hung, I. F., Poon, L. L., Law, K. I., Tang, B. S., Hon, T. Y., Chan, C. S., Chan, K. H., Ng, J. S., Zheng, B. J., Ng, W. L., Lai, R. W., Guan, Y., and Yuen, K. Y. (2003) Clinical progression and viral load in a community outbreak of coronavirus-associated SARS pneumonia: A prospective study, Lancet 361, 1767-1772.

2. Ksiazek, T. G., Erdman, D., Goldsmith, C. S., Zaki, S. R., Peret, T., Emery, S., Tong, S., Urbani, C., Comer, J. A., Lim, W., Rollin, P. E., Dowell, S. F., Ling, A. E., Humphrey, C. D., Shieh, W. J., Guarner, J., Paddock, C. D., Rota, P., Fields, B., DeRisi, J., Yang, J. Y., Cox, N., Hughes, J. M., LeDuc, J. W., Bellini, W. J., and Anderson, L. J. (2003) A novel coronavirus associated with severe acute respiratory syndrome, N. Engl. J. Med. 348, 1953-1966.

3. Marra, M. A., Jones, S. J., Astell, C. R., Holt, R. A., BrooksWilson, A., Butterfield, Y. S., Khattra, J., Asano, J. K., Barber, S. A., Chan, S. Y., Cloutier, A., Coughlin, S. M., Freeman, D., Girn, N., Griffith, O. L., Leach, S. R., Mayo, M., McDonald, H., Montgomery, S. B., Pandoh, P. K., Petrescu, A. S., Robertson, A. G., Schein, J. E., Siddiqui, A., Smailus, D. E., Stott, J. M., Yang, G. S., Plummer, F., Andonov, A., Artsob, H., Bastien, N., Bernard, K., Booth, T. F., Bowness, D., Czub, M., Drebot, M., Fernando, L., Flick, R., Garbutt, M., Gray, M., Grolla, A., Jones, S., Feldmann, H., Meyers, A., Kabani, A., Li, Y., Normand, S., Stroher, U., Tipples, G. A., Tyler, S., Vogrig, R., Ward, D., Watson, B., Brunham, R. C., Krajden, M., Petric, M., Skowronski, D. M., Upton, C., and Roper, R. L. (2003) The genome sequence of the SARS-associated coronavirus, Science 300, 1399-1404.

4. Rota, P. A., Oberste, M. S., Monroe, S. S., Nix, W. A., Campagnoli, R., Icenogle, J. P., Penaranda, S., Bankamp, B., Maher, K., Chen, M. H., Tong, S., Tamin, A., Lowe, L., Frace, M., DeRisi, J. L., Chen, Q., Wang, D., Erdman, D. D., Peret, T. C., Burns, C., Ksiazek, T. G., Rollin, P. E., Sanchez, A., Liffick, S., Holloway, B., Limor, J., McCaustland, K., Olsen-Rasmussen, M., Fouchier, R., Gunther, S., Osterhaus, A. D., Drosten, C., Pallansch, M. A., Anderson, L. J., and Bellini, W. J. (2003) Characterization of a novel coronavirus associated with severe acute respiratory syndrome, Science 300, 1394-1399.

5. Ruan, Y. J., Wei, C. L., Ee, A. L., Vega, V. B., Thoreau, H., Su, S. T., Chia, J. M., Ng, P., Chiu, K. P., Lim, L., Zhang, T., Peng, C. K., Lin, E. O., Lee, N. M., Yee, S. L., Ng, L. F., Chee, R. E., Stanton, L. W., Long, P. M., and Liu, E. T. (2003) Comparative full-length genome sequence analysis of 14 SARS coronavirus isolates and common mutations associated with putative origins of infection, Lancet 361, 1779-1785.

6. Snijder, E. J., Bredenbeek, P. J., Dobbe, J. C., Thiel, V., Ziebuhr, J., Poon, L. L., Guan, Y., Rozanov, M., Spaan, W. J., and Gorbalenya, A. E. (2003) Unique and conserved features of genome and proteome of SARS-coronavirus, an early split-off from the coronavirus group 2 lineage, J. Mol. Biol. 331, 9911004.

7. Thiel, V., Ivanov, K. A., Putics, A., Hertzig, T., Schelle, B., Bayer, S., Weissbrich, B., Snijder, E. J., Rabenau, H., Doerr, H. W., Gorbalenya, A. E., and Ziebuhr, J. (2003) Mechanisms and enzymes involved in SARS coronavirus genome expression, $J$. Gen. Virol. 84, 2305-2315.

8. Gao, F., Ou, H. Y., Chen, L. L., Zheng, W. X., and Zhang, C. T. (2003) Prediction of proteinase cleavage sites in polyproteins of coronaviruses and its applications in analyzing SARS-CoV genomes, FEBS Lett. 553, 451-456.

9. Baker, S. C., Shieh, C. K., Soe, L. H., Chang, M. F., Vannier, D. M., and Lai, M. M. (1989) Identification of a domain required for autoproteolytic cleavage of murine coronavirus gene A polyprotein, J. Virol. 63, 3693-3699.

10. Gorbalenya, A. E., Koonin, E. V., and Lai, M. M. (1991) Putative papain-related thiol proteases of positive-strand RNA viruses. Identification of rubi- and aphthovirus proteases and delineation of a novel conserved domain associated with proteases of rubi-, alpha-, and coronaviruses, FEBS Lett. 288, 201-205.

11. Bonilla, P. J., Hughes, S. A., and Weiss, S. R. (1997) Characterization of a second cleavage site and demonstration of activity in trans by the papain-like proteinase of the murine coronavirus mouse hepatitis virus strain A59, J. Virol. 71, 900-909.

12. Herold, J., Gorbalenya, A. E., Thiel, V., Schelle, B., and Siddell, S. G. (1998) Proteolytic processing at the amino terminus of human coronavirus $229 \mathrm{E}$ gene 1-encoded polyproteins: Identification of a papain-like proteinase and its substrate, J. Virol. 72, 910918.

13. Kanjanahaluethai, A., and Baker, S. C. (2000) Identification of mouse hepatitis virus papain-like proteinase 2 activity, $J$. Virol. 74, 7911-7921.

14. Ziebuhr, J., Thiel, V., and Gorbalenya, A. E. (2001) The autocatalytic release of a putative RNA virus transcription factor from its polyprotein precursor involves two paralogous papainlike proteases that cleave the same peptide bond, J. Biol. Chem. 276, 33220-33232.

15. Lim, K. P., and Liu, D. X. (1998) Characterisation of a papainlike proteinase domain encoded by ORF1a of the coronavirus IBV and determination of the C-terminal cleavage site of an $87 \mathrm{kDa}$ protein, Adv. Exp. Med. Biol. 440, 173-184.

16. Lim, K. P., Ng, L. F., and Liu, D. X. (2000) Identification of a novel cleavage activity of the first papain-like proteinase domain encoded by open reading frame 1a of the coronavirus Avian infectious bronchitis virus and characterization of the cleavage products, J. Virol. 74, 1674-1685.

17. Lim, K. P., and Liu, D. X. (1998) Characterization of the two overlapping papain-like proteinase domains encoded in gene 1 of the coronavirus infectious bronchitis virus and determination of the C-terminal cleavage site of an 87-kDa protein, Virology 245 , 303-312.

18. Herold, J., Siddell, S. G., and Gorbalenya, A. E. (1999) A human RNA viral cysteine proteinase that depends upon a unique $\mathrm{Zn}^{2+}$ binding finger connecting the two domains of a papain-like fold, J. Biol. Chem. 274, 14918-14925.

19. Bonilla, P. J., Pinon, J. L., Hughes, S., and Weiss, S. R. (1995) Characterization of the leader papain-like protease of MHV-A59, Adv. Exp. Med. Biol. 380, 423-430.

20. Harcourt, B. H., Jukneliene, D., Kanjanahaluethai, A., Bechill, J., Severson, K. M., Smith, C. M., Rota, P. A., and Baker, S. C. (2004) Identification of severe acute respiratory syndrome coronavirus replicase products and characterization of papain-like protease activity, J. Virol. 78, 13600-13612.

21. Bonilla, P. J., Hughes, S. A., Pinon, J. D., and Weiss, S. R. (1995) Characterization of the leader papain-like proteinase of MHVA59: Identification of a new in vitro cleavage site, Virology 209 489-497.

22. Kanjanahaluethai, A., Jukneliene, D., and Baker, S. C. (2003) Identification of the murine coronavirus MP1 cleavage site recognized by papain-like proteinase $2, \mathrm{~J}$. Virol. 77, 7376-7382.

23. Teng, H., Pinon, J. D., and Weiss, S. R. (1999) Expression of murine coronavirus recombinant papain-like proteinase: Efficient cleavage is dependent on the lengths of both the substrate and the proteinase polypeptides, J. Virol. 73, 2658-2666.

24. Chen, Y. S., Chien, C. H., Goparaju, C. M., Hsu, J. T., Liang, P H., and Chen, X. (2004) Purification and characterization of human prolyl dipeptidase DPP8 in Sf9 insect cells, Protein Expression Purif. 35, 142-146.

25. Sambrook, J., Fritsch, E. F., and Maniatis, T. (1989) Molecular Cloning: A Laboratory Manual, Cold Spring Harbor Laboratory, Cold Spring Harbor, New York.

26. Chien, C. H., Huang, L. H., Chou, C. Y., Chen, Y. S., Han, Y. S., Chang, G. G., Liang, P. H., and Chen, X. (2004) One site mutation disrupts dimer formation in human DPP-IV proteins, J. Biol. Chem. 279, 52338-52345.

27. Melo, R. L., Alves, L. C., Del Nery, E., Juliano, L., and Juliano, M. A. (2001) Synthesis and hydrolysis by cysteine and serine proteases of short internally quenched fluorogenic peptides, Anal. Biochem. 293, 71-77.

28. Polgar, L. (2002) The prolyl oligopeptidase family. Cell Mol. Life Sci. 59, 349-362.

29. Brocklehurst, K. (1996) Physical Factors Affecting Enzyme Activity. A. pH-Dependent Kinetics, Vol. A, BIOS Scientific Publisher Ltd., Oxford, U.K.

30. Dixon, M., and Webb, E. C. (1979) Enzymes, 3rd ed., Academic Press, New York. 
31. Bromme, D., Nallaseth, F. S., and Turk, B. (2004) Production and activation of recombinant papain-like cysteine proteases, Methods 32, 199-206.

32. Berger, A., and Schechter, I. (1970) Mapping the active site of papain with the aid of peptide substrates and inhibitors, Philos. Trans. R. Soc. London, Ser. B 257, 249-264.

33. Kuo, C. J., Chi, Y. H., Hsu, J. T., and Liang, P. H. (2004) Characterization of SARS main protease and inhibitor assay using a fluorogenic substrate, Biochem. Biophys. Res. Commun. 318, $862-867$

34. Pinitglang, S., Watts, A. B., Patel, M., Reid, J. D., Noble, M. A., Gul, S., Bokth, A., Naeem, A., Patel, H., Thomas, E. W., Sreedharan, S. K., Verma, C., and Brocklehurst, K. (1997) A classical enzyme active center motif lacks catalytic competence until modulated electrostatically, Biochemistry 36, 9968-9982.

35. Storer, A. C., and Menard, R. (1994) Catalytic mechanism in papain family of cysteine peptidases, Methods Enzymol. 244, 486500.

36. Dong, S., and Baker, S. C. (1994) Determinants of the p28 cleavage site recognized by the first papain-like cysteine proteinase of murine coronavirus, Virology 204, 541-549.

37. Hughes, S. A., Bonilla, P. J., and Weiss, S. R. (1995) Identification and analysis of MHV-A59 P28 cleavage site, Adv. Exp. Med. Biol. $380,453-458$.

38. Chouljenko, V. N., Lin, X. Q., Storz, J., Kousoulas, K. G., and Gorbalenya, A. E. (2001) Comparison of genomic and predicted amino acid sequences of respiratory and enteric bovine coronaviruses isolated from the same animal with fatal shipping pneumonia, J. Gen. Virol. 82, 2927-2933.

39. Lewis, S. D., Johnson, F. A., Ohno, A. K., and Shafer, J. A. (1978) Dependence of the catalytic activity of papain on the ionization of two acidic groups, J. Biol. Chem. 253, 5080-5086.

40. Menard, R., Khouri, H. E., Plouffe, C., Laflamme, P., Dupras, R., Vernet, T., Tessier, D. C., Thomas, D. Y., and Storer, A. C. (1991) Importance of hydrogen-bonding interactions involving the side chain of Asp158 in the catalytic mechanism of papain, Biochemistry 30, 5531-5538.

41. Vernet, T., Tessier, D. C., Chatellier, J., Plouffe, C., Lee, T. S., Thomas, D. Y., Storer, A. C., and Menard, R. (1995) Structural and functional roles of asparagine 175 in the cysteine protease papain, J. Biol. Chem. 270, 16645-16652.

42. Berti, P. J., and Storer, A. C. (1995) Alignment/phylogeny of the papain superfamily of cysteine proteases, J. Mol. Biol. 246, 273283.
43. Turk, B., Turk, V., and Turk, D. (1997) Structural and functional aspects of papain-like cysteine proteinases and their protein inhibitors, Biol. Chem. 378, 141-150.

44. Hughes, S. A., Bonilla, P. J., and Weiss, S. R. (1995) Identification of the murine coronavirus p28 cleavage site, J. Virol. 69, 809813.

45. Kim, J. C., Spence, R. A., Currier, P. F., Lu, X., and Denison, M. R. (1995) Coronavirus protein processing and RNA synthesis is inhibited by the cysteine proteinase inhibitor E64d, Virology 208 $1-8$.

46. Piccone, M. E., Zellner, M., Kumosinski, T. F., Mason, P. W., and Grubman, M. J. (1995) Identification of the active-site residues of the L proteinase of foot-and-mouth disease virus, J. Virol. 69, 4950-4956.

47. Gorbalenya, A. E., Snijder, E. J., and Spaan, W. J. (2004) Severe acute respiratory syndrome coronavirus phylogeny: Toward consensus, J. Virol. 78, 7863-7866.

48. Gosert, R., Kanjanahaluethai, A., Egger, D., Bienz, K., and Baker, S. C. (2002) RNA replication of mouse hepatitis virus takes place at double-membrane vesicles, J. Virol. 76, 3697-3708.

49. Shi, S. T., Schiller, J. J., Kanjanahaluethai, A., Baker, S. C., Oh, J. W., and Lai, M. M. (1999) Colocalization and membrane association of murine hepatitis virus gene 1 products and de novosynthesized viral RNA in infected cells, J. Virol. 73, 5957-5969.

50. van der Meer, Y., Snijder, E. J., Dobbe, J. C., Schleich, S., Denison, M. R., Spaan, W. J., and Locker, J. K. (1999) Localization of mouse hepatitis virus nonstructural proteins and RNA synthesis indicates a role for late endosomes in viral replication, J. Virol. $73,7641-7657$.

51. Mossad, S. B. (2003) Effect of zincum gluconicum nasal gel on the duration and symptom severity of the common cold in otherwise healthy adults, Qjm 96, 35-43.

52. Brewer, G. J., Johnson, V. D., Dick, R. D., Hedera, P., Fink, J. K., and Kluin, K. J. (2000) Treatment of Wilson's disease with zinc. 17: treatment during pregnancy, Hepatology 31, 364-370.

53. Hsu, J. T., Kuo, C. J., Hsieh, H. P., Wang, Y. C., Huang, K. K., Lin, C. P., Huang, P. F., Chen, X., and Liang, P. H. (2000) Evaluation of metal-conjugated compounds as inhibitors of 3CL protease of SARS-CoV, FEBS Lett. 574, 116-120.

BI0504761 